\title{
Burn-induced heterotopic ossification from incidence to therapy: key signaling pathways underlying ectopic bone formation
}

\author{
Xianglin $\mathrm{Hu}^{1,2+} \mathbb{0}$, Zhengwang Sun ${ }^{1,2+}$, Fengfeng $\mathrm{Li}^{3 \dagger}$, Chaoyin Jiang ${ }^{4^{*}}$, Wangjun Yan ${ }^{1,2^{*}}$ and Yangbai Sun ${ }^{1,2,5^{*}}$
}

\author{
${ }^{*}$ Correspondence: \\ hunball2@163.com; \\ yanwj@fudan.edu.cn; \\ drsunyb@fudan.edu.cn \\ ${ }^{\dagger}$ Xianglin $\mathrm{Hu}$, Zhengwang \\ Sun and Fengfeng Li \\ contributed equally to this \\ work \\ 'Department \\ of Musculoskeletal \\ Surgery, Fudan University \\ Shanghai Cancer Center, \\ Shanghai 200032, China ${ }^{4}$ \\ Department of Orthopedic \\ Surgery, Shanghai Sixth \\ People's Hospital, Shanghai \\ Jiaotong University, \\ Shanghai 200233, China \\ Full list of author information \\ is available at the end of the \\ article
}

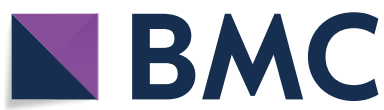

(O) The Author(s), 2021. Open Access This article is licensed under a Creative Commons Attribution 4.0 International License, which permits use, sharing, adaptation, distribution and reproduction in any medium or format, as long as you give appropriate credit to the original author(s) and the source, provide a link to the Creative Commons licence, and indicate if changes were made. The images or other third party material in this article are included in the article's Creative Commons licence, unless indicated otherwise in a credit line to the material. If material is not included in the article's Creative Commons licence and your intended use is not permitted by statutory regulation or exceeds the permitted use, you will need to obtain permission directly from the copyright holder. To view a copy of this licence, visit http:/ creativecommons.org/licenses/by/4.0/.
Keywords: Burn injury, Heterotopic ossification, Incidence, Risk factor, Signaling pathway, Mechanism

\section{Introduction}

Burn injury refers to tissue damage caused by various heat factors. These include thermal sources (fire, hot liquid and metal, and superheated steam), chemical substances (acids and alkalis), high voltages, and radiation [1-3]. The burn depth and area are the most important determining factors of burn severity [4]. Burn injuries generally occur to the skin and mucous membranes, although subcutaneous and submucosal tissues, muscles, bones, and even internal organs can be injured in severe cases [5-7]. Because the normal skin barrier function is impaired, severe burns often cause extensive tissue 
necrosis and fluid exudation, accompanied by shock, infection, sepsis, multiple organ dysfunction syndrome (MODS) and even death [8-10].

The pathophysiology of burns is complex, with substantial inflammatory, immune and metabolic reactions throughout their course. Patients with severe burns may experience stages of fluid exudation, acute infection, wound healing and rehabilitation [11]. Based on the latest expert opinions, wound healing is only a medium-term goal: complete recovery must address long-term complications as well as improving patient mental health and quality of life [12]. The sequelae of severe burn injury include local scarring, contracture deformity, and hypofunction of vital organs such as the heart, brain and kidneys [13-16].

Heterotopic ossification $(\mathrm{HO})$ is a rare but debilitating pathological condition in which true bone tissue occurs and matures in soft tissues [17]. Unlike calcification lesions, HO leads to a complete bone microenvironment with bone tissue cells, microcirculation and neuroendocrine function $[18,19]$. HO patients can experience pain and limited range of motion (ROM), which seriously impairs their daily life [20]. Burn injury is a significant source of acquired HO [21]. Burn-induced HO has been characterized in many clinical and preclinical studies and the related molecular mechanisms are gradually being elucidated.

In this review, we summarize the clinical characteristics and potential mechanisms of burn-induced $\mathrm{HO}$. We also indicate the current challenges and future directions in the research and treatment of burn-induced $\mathrm{HO}$.

\section{Clinical characteristics of burn-induced HO}

\section{Incidence and risk factors}

$\mathrm{HO}$ incidence after burn injury is influenced by a number of factors. Levi et al. [21] collected data on 2797 patients with burn injury from six burn centers in America and found that 98 patients developed HO (an incidence of 3.5\%). Dependent risk factors included arm burns requiring skin grafts $(\mathrm{OR}=96.4,95 \% \mathrm{CI} 1.19-7806)$; burns covering more than $30 \%$ of the total body surface area (TBSA; OR $=11.5,95 \%$ CI6.0-21.9); multiple trips to the operating room $(\mathrm{OR}=1.32,95 \% \mathrm{CI} 1.18-1.40)$; and the number of days on a ventilator $(\mathrm{OR}=1.034,95 \%$ CI1.03-1.04) [21]. Similarly, Schneider et al. [22] identified that percentage TBSA and need for skin grafts on the arm, head, neck and trunk are the remarkable predictors for HO. Thefenne et al. [23] enrolled 805 patients at a burn center in France and found that 32 patients later developed HO (an incidence of $4.0 \%)$. The use of a fluidized bed $(\mathrm{OR}=39.6,95 \% \mathrm{CI} 10.4-150.5)$, curare use ( $\mathrm{OR}=24.1$, 95\% CI8.3-70.5), pulmonary infection ( $\mathrm{OR}=21.5$, 95\% CI6.0-77.4), cutaneous infection $(\mathrm{OR}=7.5,95 \% \mathrm{CI} 3.0-18.6)$, the length of stay in the intensive care unit $(\mathrm{OR}=1.1$, 95\% CI1.1-1.2), the mean total burn area (OR $=1.1,95 \%$ CI1.1-1.2), mean depth of the burns $(\mathrm{OR}=1.1,95 \% \mathrm{CI} 1.1-1.2)$ were found to be independent risk factors for $\mathrm{HO}$ [23]. Orchard et al. [24] enrolled 337 patients at a burn center in Australia and found that 19 patients later developed HO (an incidence of 5.6\%). A greater percentage TBSA, inhalation injury, mechanical ventilation, the number of surgical treatments, sepsis, and longer time to active movement were found to be associated with $\mathrm{HO}$ in that study [24].

Based on the three large burn center reports mentioned [21, 23, 24], we summarized that the incidence of $\mathrm{HO}$ in burn injury is about $3.5-5.6 \%$ (Table 1). Patients with 


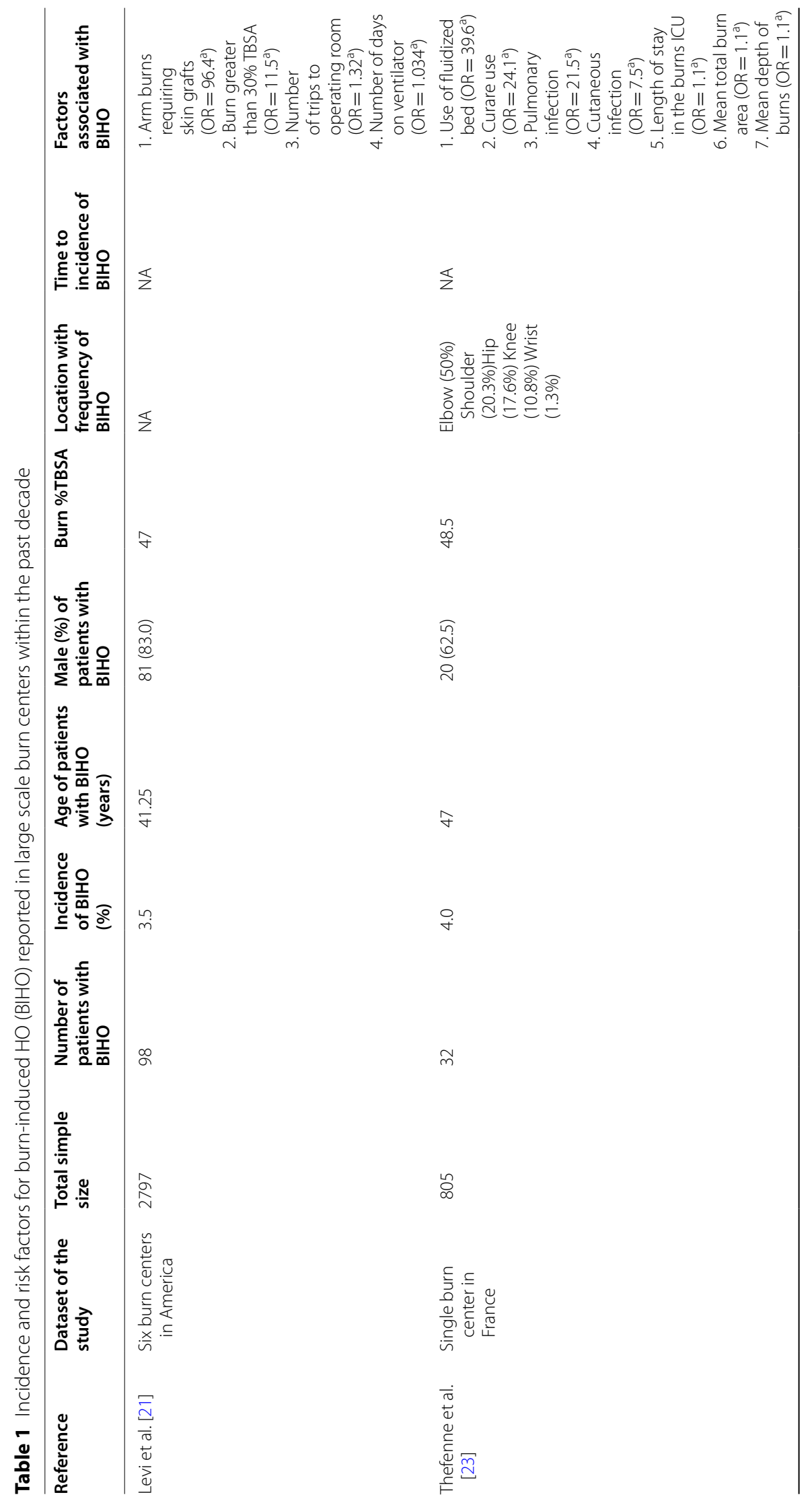




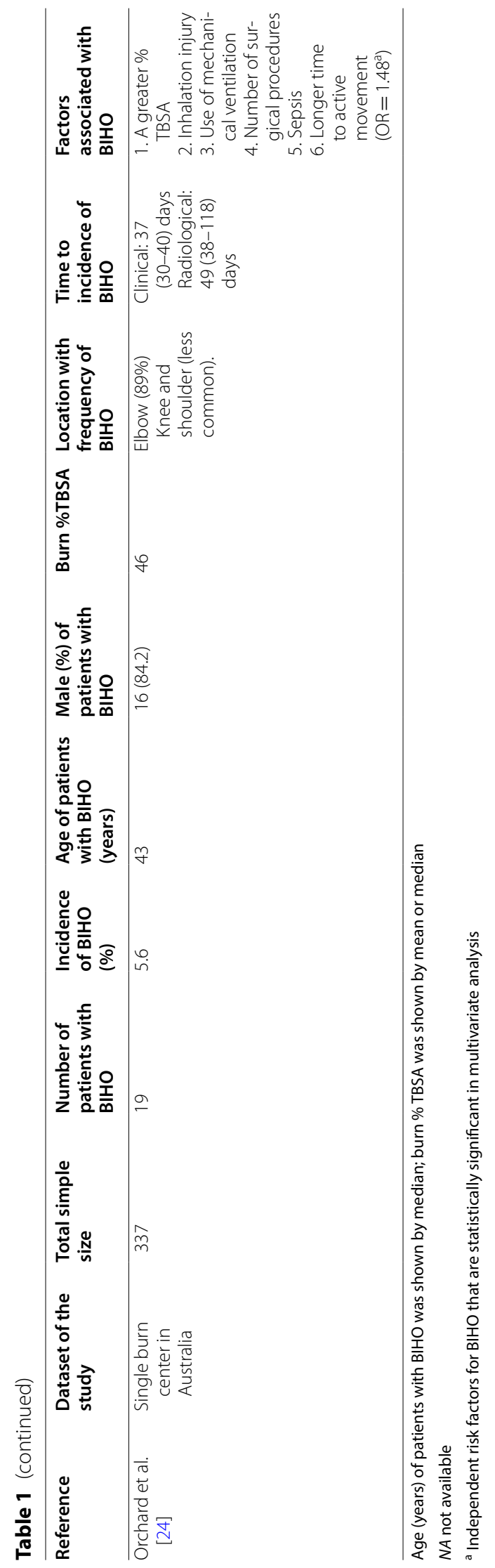


burn-induced $\mathrm{HO}$ are mainly middle-aged people and males. The mean or median burn percentage TBSA associated with HO incidence is about $46-48.5 \%$. The elbow is the most common site of burn-induced HO [21, 23, 24]. Larger percentage TBSA affected, burns requiring skin grafts, and burns necessitating pulmonary intensive care are the currently well-recognized risk factors for burn-induced HO. In addition, Klein et al. [25] found that a longer time to wound closure significantly increases the risk of burninduced $\mathrm{HO}$ in the elbow.

\section{Presentation and diagnosis of burn-induced $\mathrm{HO}$}

Patient-reported movement restrictions and intractable pain are early signs of burninduced HO. Patients can feel that their joints are locked or fused, with less ROM and sharp stabbing pains (nerve compression) [26]. A study from the Burn Model System National Database found that the presence of HO significantly increases the absolute loss of elbow flexion (adjusted median of $23.5^{\circ}$ ), which causes more serious elbow contracture [27]. Moreover, burn-induced HO not only causes physical limitations but also psychological burdens, such as worry and distress [26]. In turn, HO can induce recurrent non-healing ulcers in the old burn scar [28].

Given their history of burns and these early manifestations, patients with $\mathrm{HO}$ can easily be diagnosed through imaging examinations, such as X-ray, computer tomography (CT) and magnetic resonance imaging (MRI) [29]. X-ray is a common examination for $\mathrm{HO}$ but only applies to mature $\mathrm{HO}$ lesions as it rarely identifies early-stage $\mathrm{HO}$ lesions. CT scans can identify tiny HO lesions early and clearly display their shape and structure [30]. MRI displays the surrounding soft tissues and can better reveal $\mathrm{HO}$ when used in combination with CT [31]. Although positron emission tomography-CT (PET-CT) and radionuclide bone scanning can diagnose $\mathrm{HO}$ with high sensitivity and specificity [32], their high costs and requirement for radioactive substances limit their use. They are not routinely recommended for $\mathrm{HO}$ in clinical practice. Representative imaging materials of a patient with burn-induced $\mathrm{HO}$ are shown in Fig. 1.

\section{Signaling pathways and mediators underlying burn-induced HO}

Normal soft tissues do not have the three basic conditions required for osteogenesis, namely osteogenic precursor cells, osteogenic signal induction factors and the appropriate local microenvironment [33,34]. It is important to investigate which cells seed in soft tissues and develop into pre-osteoblasts. The main reported potential osteogenic precursor cells (seeds) for HO are endothelial cells, muscle satellite cells, mesenchymal stem cells (MSCs), adipose-derived stem cells (ASCs), fibroblasts, tendon cells and progenitor cells [35-40]. Herein, we discuss the signaling pathways involved in burn-induced $\mathrm{HO}$ based on the current evidence (Fig. 2; Table 2).

\section{Vessel- and endothelial cell-based pathways in burn-induced HO}

Burn injury can cause local tissue edema and hypoxia, with a significant impact on the microvascular system. Capillary basement membrane and endothelial cells are generally impaired during a burn injury [41, 42]. In the mouse model established by Peterson et al. [43], burn injury was found to increase early vascularization and subsequent 

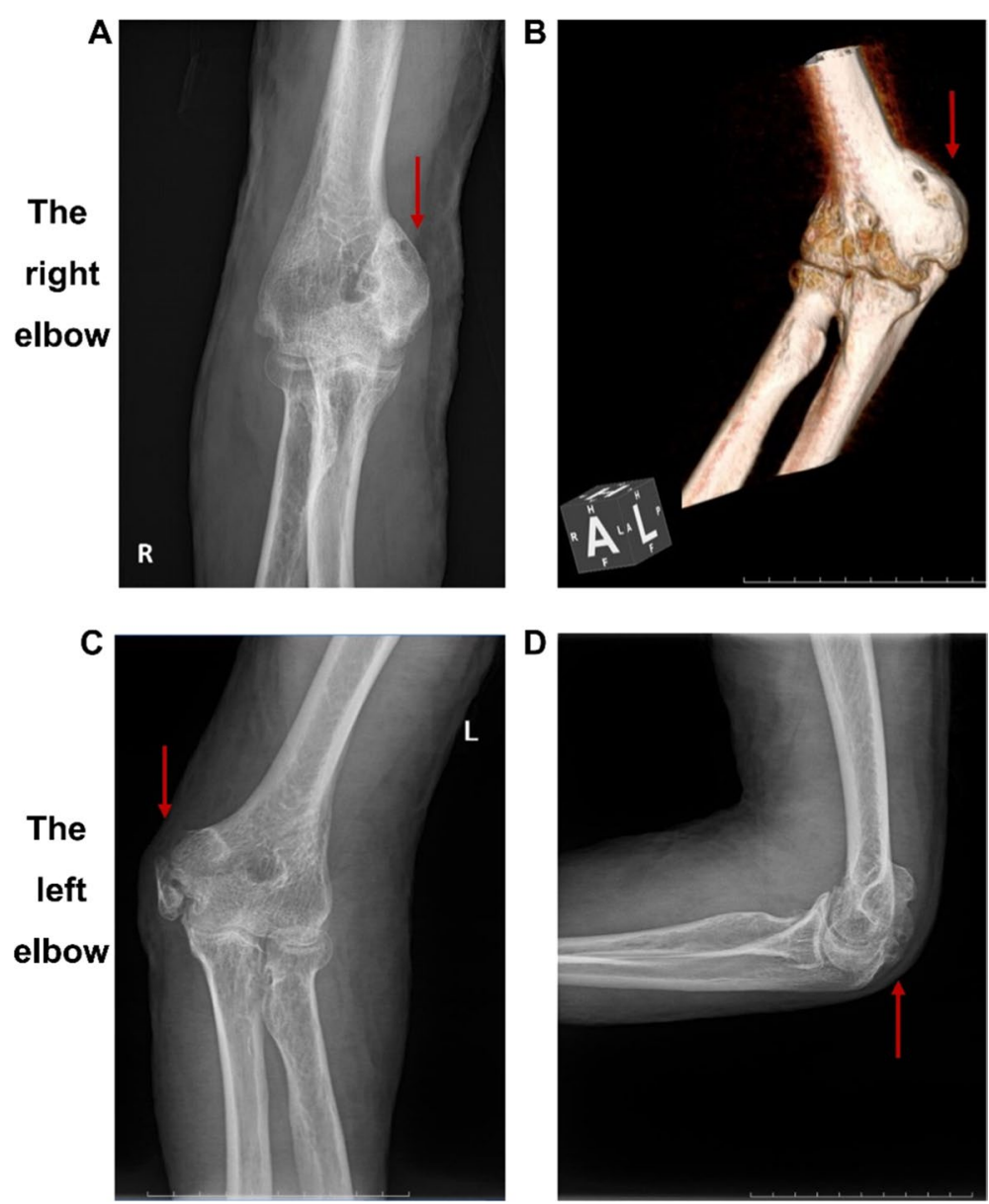

Fig. 1 Representative imaging of burn-induced $\mathrm{HO}$ in the elbow. A 40-year old male patient suffered extensive thermal burn injury (80\% TBSA). He complained of limitation in the range of movement of his bilateral elbow joints 3 months after the burn injury. He was diagnosed with burn-induced $\mathrm{HO}$ of both elbows via imaging examinations. A X-ray of the right elbow. B 3D reconstruction of CT on the right elbow. $\mathbf{C}$, D X-rays of the left elbow. The red arrows indicate the $\mathrm{HO}$ lesions

HO. It also increases tumor necrosis factor- $\alpha$ (TNF- $\alpha$ ) secretion and the vascularization of ossicles [43]. Tissue hypoxia following burn injury plays a key role in the initiation of vascularization of ossicles. Hypoxia begins $48 \mathrm{~h}$ after the burn injury and peaks on day 3 (within the burn-healing margin), with significant expression of hypoxiainducible factor-1 (HIF-1) and vascular endothelial growth factor (VEGF) [44, 45]. VEGF has a potent bone regeneration ability $[46,47]$. Behr et al. [48] found that VEGF-A not only increases osteogenic differentiation of ASCs in vitro and in vivo, but also enhances angiogenesis of ASCs. On the other hand, using a mouse model of tenotomy with dorsal burn injury-induced HO, Agarwal et al. [49] found that VECadherin-cre (a marker of endothelial cells) is positive in HO. This indicates that local and circulating endothelial cells may transform into potential osteogenic precursor cells via endothelial-to-mesenchymal transition (EMT). Bone morphogenetic protein 


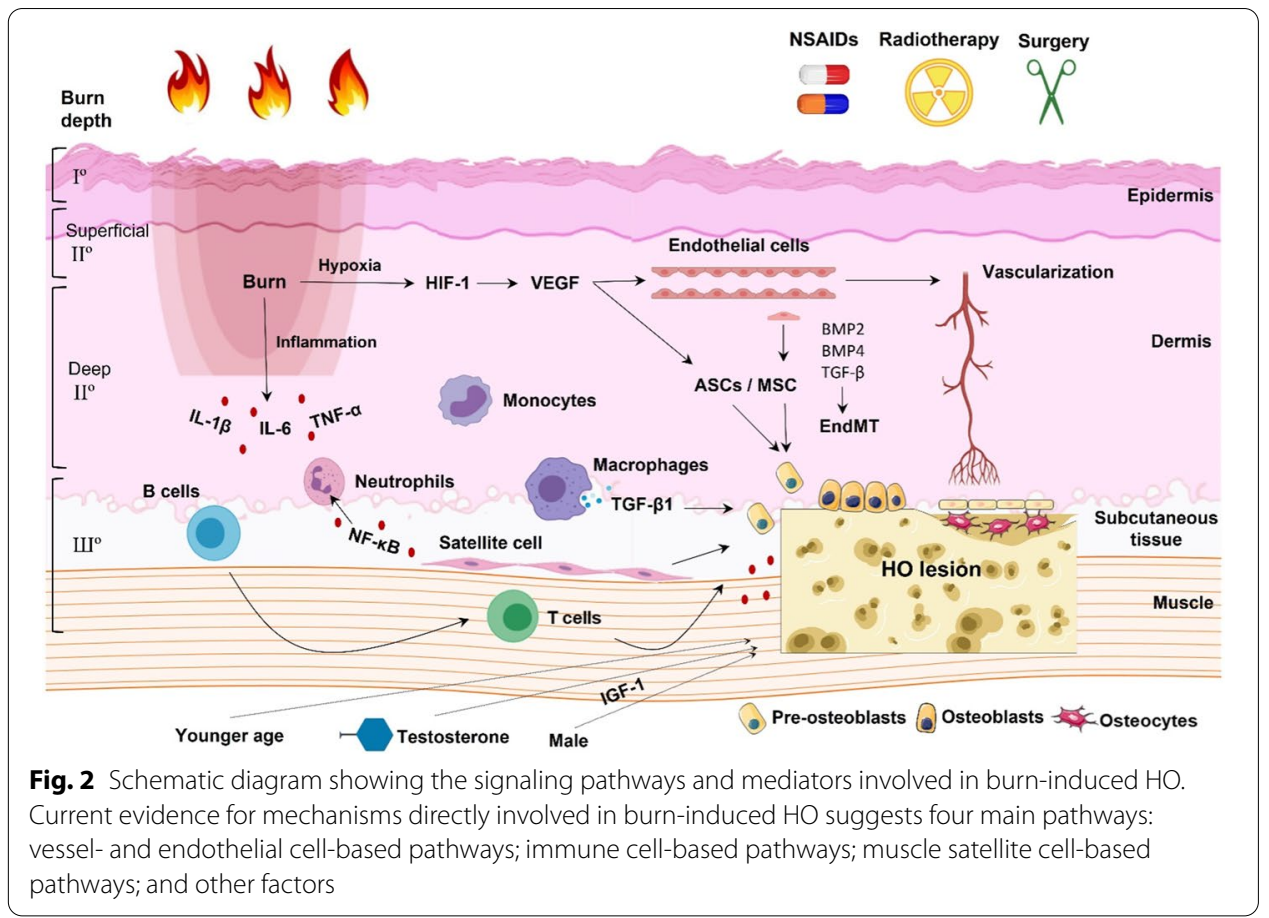

Table 2 Key signaling pathways and potential mediators underlying burn-induced $\mathrm{HO}$

\begin{tabular}{llc}
\hline Signaling pathway & Potential mediator & References \\
\hline Vessel- and endothelial cell-based pathways & HIF-1, VEGF, ASCS/MSCS & {$[43-50]$} \\
Immune cell-based pathways & BMP2, BMP4, TGF- $\beta$, EMT & \\
& TNF- - , IL-6, IL-1 $\beta$, neutrophils and mono- & {$[51-54]$} \\
& Cytes & \\
& CXCL1, CXCL2, MCP-1, G-CSF, GM-CSF and \\
& TGF- $\beta$, macrophages & \\
& T cells and B cells & \\
Muscle satellite cell-based pathways & NF-KB, neutrophils, Rho signaling & {$[55-59]$} \\
Other factors (age, gender etc.) & Smad, NF-KB, IGF-1, testosterone & {$[60-62]$} \\
\hline
\end{tabular}

2 (BMP-2), BMP-4 and transforming growth factor- $\beta$ (TGF- $\beta$ ) are considered to be the key players in EMT in $\mathrm{HO}$ [50].

\section{Immune cell-based pathways in burn-induced HO}

Hyper-inflammatory levels (inflammatory cells and cytokines) and immunosuppression status are known in burn injury. The levels of serum TNF- $\alpha$, interleukin 6 (IL-6), IL-1 $\beta$, neutrophils and monocytes significantly increase while lymphocyte levels decrease following burn injury [51]. In a burn/tenotomy-induced HO mouse model, the site of injury shows a high local increase in the levels of monocytes and neutrophil-associated chemokines and cytokines, including CXCL1, CXCL2, monocyte chemotactic protein 1 (MCP-1), granulocyte colony-stimulating factor (G-CSF), granulocyte-macrophage colony-stimulating factor (GM-CSF) and transforming growth factor beta (TGF- $\beta$ ) [52]. The authors used single-cell RNA sequencing to show that the recruited monocytes and macrophages are the main culprits. They further revealed the TGF- $\beta 1$-expressing 
macrophages drive $\mathrm{HO}$ formation in the burn/tenotomy model in the early stages of inflammation. Besides the predominant role of macrophages, the adaptive immune system also participates in burn-induced HO. The osteogenic capacity of MSCs decreases and $\mathrm{HO}$ development is attenuated without mature $\mathrm{B}$ - and T-lymphocytes [53]. The dysregulation of immune checkpoints on $\mathrm{T}$ cells and $\mathrm{B}$ cells might be involved in $\mathrm{HO}$ development [54].

\section{Muscle satellite cell-based pathways in burn-induced HO}

Even if a cutaneous burn affects tissues isolated from skeletal muscles, it can cause myophagism, which is activity in the muscle due to neutrophils releasing nuclear factor kappa light chain enhancer of activated B cells (NF- $\mathrm{KB}$ ). Muscle progenitor cells thus respond to cutaneous thermal injury [55]. Skeletal muscle satellite cells are a type of flat cell that is attached to the surface of muscle fibers. They have the properties of stem cells: they can proliferate and differentiate to repair muscle cells when muscle fibers are injured [56]. Human muscle satellite cells have the ability to be osteoprogenitor cells, with Rho signaling acting as the switch between myogenesis and osteogenesis [57]. Wu et al. [58] indicated that skeletal muscle satellite cells are activated after cutaneous burns in rats. They can attain significant osteogenic potential after cutaneous burns, suggesting a role in burn-induced $\mathrm{HO}$ [59].

\section{Other factors associated with the mechanisms of burn-induced $\mathrm{HO}$}

Peterson et al. [60] found that burn injury in young mice is associated with a more marked increase in $\mathrm{HO}$ development, NF- $\mathrm{kB}$ activation, and osteoclast activity than is seen in old mice. MSCs of young mice show more osteogenesis in vitro and higher activations of Smad and NF-kB signaling after burn injury than that found in old mice. This might answer why patients with burn-induced $\mathrm{HO}$ are generally young to middle-aged people with a median age of $46-48.5$, as we showed above rather than old people.

Since burn-induced HO is more common in male patients $(62.5-84.2 \%$, as we showed above), a gender difference in the mechanisms of burn-induced HO was investigated [61]. In a tenotomy/burn model, MSCs from male mice showed more osteogenic gene and protein expression than those from female mice. Male mice developed 35\% more HO, which was related to increased p-Smad and insulin-like growth factor 1 (IGF-1) signaling at the HO lesion [61]. Testosterone might play a role in the gender difference of burn-induced HO. Thorpe et al. [62] found that acutely burned patients who received a testosterone analog treatment presented a higher incidence of elbow $\mathrm{HO}$ than patients without testosterone analog treatment. In a mouse model following burn/tenotomy, testosterone analog treatment conferred a trend of developing a larger volume of $\mathrm{HO}$ lesions [62].

\section{Potential neurological and calcium-related contributions to $\mathrm{HO}$ following burn injury}

Thermal nerve injury is characteristic of severe burn injuries [63, 64]. Substance P and calcitonin gene-related peptide (CGRP) released by the injured axon can mediate a neurogenic inflammatory reaction by recruiting neutrophils, macrophages and inflammatory cytokines $[65,66]$. Substance P with crosstalk of CGRP can promote the differentiation of MSCs into osteoblasts and facilitate HO development [67, 68]. Endoneurial 
progenitor cells can flow via endometrial vessels to the site of $\mathrm{HO}$ and become an important source of osteoblasts [69].

The dysregulation of calcium metabolism following severe burn injury might also participate in $\mathrm{HO}$ development. Burn-induced bone resorption can release calcium into the blood [70]. Calcium and ionized calcium levels could then increase to their normal limits during the late phase of burn injury [71]. Excessive calcium may deposit and facilitate the $\mathrm{HO}$ lesion via the nucleotide-binding oligomerization domain-like receptor protein 3 (NLRP3) inflammasome-IL-1ß pathway in macrophages [72].

\section{Prophylaxis and treatments of burn-induced HO}

Non-steroidal anti-inflammatory drugs (NSAIDs) and radiotherapy are currently the main prophylactic strategies for HO. Surgery remains the mainstream treatment for the limited joint motion and intolerable pain caused by burn-induced $\mathrm{HO}$.

\section{NSAIDs}

As mentioned above, increased inflammatory levels play a key role in $\mathrm{HO}$ development. NSAIDs are cyclooxygenase (COX) inhibitors that can reduce the production of inflammatory mediator prostaglandin (PG) and bradykinin, thus exerting anti-inflammatory, analgesic and antipyretic effects [73]. NSAIDs may block chondrogenic differentiation of MSCs to inhibit bone formation [74]. A large-scale meta-analysis including 29 studies showed that both non-selective and selective NSAIDs can effectively prevent $\mathrm{HO}$ after total hip arthroplasty. The non-selective NSAID indomethacin and the selective NSAID celecoxib are commonly prescribed [75]. A subsequent updated Bayesian network metaanalysis also confirmed the effective role of celecoxib as a prophylaxis of HO [76]. However, it is worth noting that NSAIDs may delay bone healing [77, 78]. Thus, the dose and course of NSAID treatment should be individualized. To date, there is still no direct study exploring NSAID use in prophylaxis for burn-induced HO.

\section{Radiotherapy}

Radiotherapy with a medium biologically effective dose from 20 to 24 Gy has proven to be an effective prophylaxis for HO after total hip arthroplasty. Preoperative and postoperative radiotherapy have similar prophylactic efficacy while multiple fractions might be more effective than single-fraction radiotherapy [79]. An in vitro experiment showed that radiotherapy can suppress the BMP2 signaling pathway in MSCs, thus interfering with BMP2-mediated osteoblastic differentiation [80]. However, it needs to be noted that radiotherapy used prophylactically for $\mathrm{HO}$ can be accompanied by toxic responses and an increased risk of secondary malignancy $[81,82]$. The requirement for radiotherapy devices and high associated costs also limit its wide application in clinical practice. Although radiotherapy has been used in the prophylaxis of trauma-induced $\mathrm{HO}$, there is still no direct evidence for its efficacy.

\section{Surgery of burn-induced $\mathrm{HO}$}

Surgery of burn-induced $\mathrm{HO}$ can rapidly relieve the issues of limited joint motion and pain, allowing patients to regain ability. The mean ROM significantly increased from $31^{\circ}$ preoperatively to $99^{\circ}$ postoperatively [83]. Passive ROM exercise and continuous 
physical therapy (rehabilitation) are suggested to begin on day 1 after surgery [84]. It is worth noting that $\mathrm{HO}$ might recur even after surgery. The re-emergence of MSCs in excision sites marked by platelet-derived growth factor receptor- $\alpha$ (PDGFR $\alpha$ ) expression might be the reason for this recurrence [85]. Maender et al. [86] recommend perioperative radiotherapy to decrease $\mathrm{HO}$ recurrence.

\title{
Conclusion and prospects
}

There are fewer direct preclinical and clinical studies of burn-induced HO than of trauma- and nerve-related HO. Here, we looked at burn-induced HO from bedside to bench and back. Since burns involve such complex pathophysiological processes with numerous molecular signals, it is urgent to elucidate the mechanisms of $\mathrm{HO}$ in the specific context of burn injury. How do the signaling pathways and mediators interact in burn-induced HO? What is the signaling network for burn-induced HO? Which mediators are ultimately responsible for $\mathrm{HO}$ following burn injury? Answering these questions will facilitate our current understanding of burn-induced HO.

In addition to clinical risk factors, effective serum biomarkers for prediction of $\mathrm{HO}$ occurrence after burn injury should be established. Moreover, the bio-prophylactic and bio-therapeutic strategies based on the discussed molecules and signaling pathways should be actively developed for burn-induced HO.

\begin{abstract}
Abbreviations
MODS: Multiple organ dysfunction syndrome; HO: Heterotopic ossification; ROM: Range(s) of motion; TBSA: Total body surface area; CT: Computed tomography; MRI: Magnetic resonance imaging; PET-CT: Positron emission tomography-CT; MSCs: Mesenchymal stem cells; ASCs: Adipose-derived stem cells; TNF-a: Tumor necrosis factor-a; HIF-1: Hypoxia-inducible factor-1; VEGF: Vascular endothelial growth factor; BMP: Bone morphogenetic protein; TGF- $\beta$ : Transforming growth factor- $\beta$; EMT: Endothelial-to-mesenchymal transition; IL: Interleukin; CXCL1: Chemokine ligand 1; CXCL2: Chemokine ligand 2; MCP-1: Monocyte chemotactic protein 1; NF-KB: Nuclear factor kappa-light-chain-enhancer of activated B cells; IGF-1: Insulin-like growth factor 1; CGRP: Calcitonin gene-related peptide; NLRP3: Nucleotide-binding oligomerization domain-like receptor protein 3; NSAIDs: Non-steroidal anti-inflammatory drugs; PG: Prostaglandin; COX: Cyclooxygenase; PDGFRa: Platelet-derived growth factor receptor-a; BIHO: Burn-induced $\mathrm{HO}$ (used in tables only).
\end{abstract}

Acknowledgements

We would like to thank the patient who offered the medical imaging materials in this study.

\section{Authors' contributions}

YS, WY and $\mathrm{CJ}$ contributed to the concept of the review and case report. XH, ZS, FL contributed to the literature research and graphics. XH drafted the manuscript. YS, WY, CJ, ZS and FL revised the manuscript. All authors read and approved the final manuscript.

\section{Funding}

This work was supported by the National Natural Science Foundation of China $(81701937,81672851$, and 81872179) and the General Scientific Research of Health and Family Planning Commission of Hainan Province (Haikou) in China (20A200388).

\section{Availability of data and materials}

Not applicable.

\section{Declarations}

Ethics approval and consent to participate

Not applicable.

\section{Competing interests}

The authors declare that they have no conflict of interest.

\section{Author details}

'Department of Musculoskeletal Surgery, Fudan University Shanghai Cancer Center, Shanghai 200032, China. ${ }^{2}$ Department of Oncology, Shanghai Medical College, Fudan University, Shanghai 200032, China. ${ }^{3}$ Department of Orthopedic Surgery, The Second Affiliated Hospital of Guangzhou Medical University, Guangzhou 510260, China. ${ }^{4}$ Department of Orthopedic Surgery, Shanghai Sixth People's Hospital, Shanghai Jiaotong University, Shanghai 200233, China. 
${ }^{5}$ Department of Plastic and Reconstructive Surgery, Shanghai Ninth People's Hospital, Shanghai Jiao Tong University School of Medicine, Shanghai 200011, China.

Received: 15 April 2021 Accepted: 20 July 2021

Published online: 27 July 2021

\section{References}

1. Martin NA, Falder S. A review of the evidence for threshold of burn injury. Burns. 2017:43(8):1624-39.

2. Akelma H, Karahan ZA. Rare chemical burns: review of the literature. Int Wound J. 2019;16(6):1330-8.

3. Coruh A. High voltage electric burn repair of the forehead by reverse flow temporalis muscle flap. J Burn Care Res. 2019:40(3):373-6.

4. Greenhalgh DG. Management of burns. N Engl J Med. 2019;380(24):2349-59.

5. Nguyen JQ, Marks HL, Everett T, et al. Early visualization of skin burn severity using a topically applied dye-loaded liquid bandage. Sci Rep. 2020;10(1):9314.

6. Ye H, De S. Thermal injury of skin and subcutaneous tissues: a review of experimental approaches and numerical models. Burns. 2017:43(5):909-32.

7. Klein GL. Disruption of bone and skeletal muscle in severe burns. Bone Res. 2015;3:15002.

8. Rech MA, Mosier MJ, McConkey K, et al. Outcomes in burn-injured patients who develop sepsis. J Burn Care Res. 2019:40(3):269-73.

9. Forbinake NA, Ohandza CS, Fai KN, et al. Mortality analysis of burns in a developing country: a CAMEROONIAN experience. BMC Public Health. 2020;20(1):1269.

10. Mariano F, Hollo' Z, Depetris N, et al. Coupled-plasma filtration and adsorption for severe burn patients with septic shock and acute kidney injury treated with renal replacement therapy. Burns. 2020;46(1):190-8.

11. Roshangar L, Soleimani Rad J, Kheirjou R, et al. Skin burns: review of molecular mechanisms and therapeutic approaches. Wounds. 2019;31(12):308-15.

12. Jeschke MG, van Baar ME, Choudhry MA, et al. Burn injury. Nat Rev Dis Primers. 2020;6(1):11

13. Oryan A, Alemzadeh E, Moshiri A. Burn wound healing: present concepts, treatment strategies and future directions. J Wound Care. 2017:26(1):5-19.

14. Hall C, Hardin C, Corkins CJ, et al. Pathophysiologic mechanisms and current treatments for cutaneous sequelae of burn wounds. Compr Physiol. 2017:8(1):371-405.

15. Wen JJ, Cummins CB, Szczesny B, et al. Cardiac dysfunction after burn injury: role of the AMPK-SIRT1-PGC1 a-NFE2L2ARE pathway. J Am Coll Surg. 2020:230(4):562-71.

16. Randolph AC, Fukuda S, Ihara K, et al. Blood-brain barrier dysfunction after smoke inhalation injury, with and without skin burn. Shock. 2019;51(5):634-49.

17. Dey D, Wheatley BM, Cholok D, et al. The traumatic bone: trauma-induced heterotopic ossification. Transl Res. 2017;186:95-111.

18. Ware AD, Brewer N, Meyers C, et al. Differential vascularity in genetic and nonhereditary heterotopic ossification. Int J Surg Pathol. 2019;27(8):859-67.

19. Gugala Z, Olmsted-Davis EA, Xiong Y, et al. Trauma-induced heterotopic ossification regulates the blood-nerve barrier. Front Neurol. 2018;9:408.

20. Herman ZJ, Edelman DG, Ilyas AM. Heterotopic ossification after elbow fractures. Orthopedics. 2021;44(1):10-6.

21. Levi B, Jayakumar P, Giladi A, et al. Risk factors for the development of heterotopic ossification in seriously burned adults: a National Institute on Disability, Independent Living and Rehabilitation Research burn model system database analysis. J Trauma Acute Care Surg. 2015;79(5):870-6.

22. Schneider JC, Simko LC, Goldstein R, et al. Predicting heterotopic ossification early after burn injuries: a risk scoring system. Ann Surg. 2017;266(1):179-84.

23. Thefenne $L$, de Brier $G$, Leclerc $T$, et al. Two new risk factors for heterotopic ossification development after severe burns. PLoS ONE. 2017;12(8):e0182303.

24. Orchard GR, Paratz JD, Blot S, et al. Risk factors in hospitalized patients with burn injuries for developing heterotopic ossification-a retrospective analysis. J Burn Care Res. 2015;36(4):465-70.

25. Klein MB, Logsetty S, Costa B, et al. Extended time to wound closure is associated with increased risk of heterotopic ossification of the elbow. J Burn Care Res. 2007;28(3):447-50.

26. Foster N, Kornhaber R, McGarry S, et al. Heterotopic ossification in adults following a burn: a phenomenological analysis. Burns. 2017:43(6):1250-62.

27. Yelvington ML, Godleski M, Lee AF, et al. A comparison of contracture severity at acute discharge in patients with and without heterotopic ossification: a burn model system national database study. J Burn Care Res. 2019;40(3):349-54.

28. Mohammadi AA, Foroutan A, Karvar M, et al. Recurrent nonhealing wound in old burn scar may be due to heterotopic ossification. Burns. 2017;43(7):1599-601.

29. Łęgosz P, Otworowski M, Sibilska A, et al. Heterotopic ossification: a challenging complication of total hip arthroplasty: risk factors, diagnosis, prophylaxis, and treatment. Biomed Res Int. 2019;2019:3860142.

30. Mourad WF, Packianathan S, Ma JK, et al. Computerized tomography-based radiotherapy improves heterotopic ossification outcomes. Bone. 2013;57(1):132-6.

31. Zagarella A, Impellizzeri E, Maiolino R, et al. Pelvic heterotopic ossification: when CT comes to the aid of MR imaging. Insights Imaging. 2013;4(5):595-603.

32. Seraj SM, Al-Zaghal A, Østergaard B, et al. Identification of heterotopic ossification using 18F-NaF PET/CT. Clin Nucl Med. 2019:44(4):319-20. 
33. Chalmers J, Gray DH, Rush J. Observations on the induction of bone in soft tissues. J Bone Joint Surg Br. 1975;57(1):36-45.

34. Yin N, Zhu L, Ding L, et al. MiR-135-5p promotes osteoblast differentiation by targeting HIF1AN in MC3T3-E1 cells. Cell Mol Biol Lett. 2019;24:51.

35. Nelson ER, Wong VW, Krebsbach PH, et al. Heterotopic ossification following burn injury: the role of stem cells. J Burn Care Res. 2012;33(4):463-70.

36. Zhang WH, Li XL, Guo Y, et al. Proliferation and osteogenic activity of fibroblasts induced with fibronectin. Braz J Med Biol Res. 2017;50(10):e6272.

37. Lees-Shepard JB, Goldhamer DJ. Stem cells and heterotopic ossification: lessons from animal models. Bone. 2018;109:178-86.

38. Feng $\mathrm{H}$, Xing W, Han $\mathrm{Y}$, et al. Tendon-derived cathepsin $\mathrm{K}$-expressing progenitor cells activate Hedgehog signaling to drive heterotopic ossification. J Clin Invest. 2020;130(12):6354-65.

39. Yu X, Wan Q, Ye X, et al. Cellular hypoxia promotes osteogenic differentiation of mesenchymal stem cells and bone defect healing via STAT3 signaling. Cell Mol Biol Lett. 2019;24:64.

40. Zhou X, Xu W, Wang Y, et al. LncRNA DNM3OS regulates GREM2 via miR-127-5p to suppress early chondrogenic differentiation of rat mesenchymal stem cells under hypoxic conditions. Cell Mol Biol Lett. 2021;26(1):22.

41. Zhuravleva $\mathrm{K}$, Goertz $\mathrm{O}$, Wölkart $\mathrm{G}$, et al. The tight junction protein cingulin regulates the vascular response to burn injury in a mouse model. Microvasc Res. 2020;132:104067.

42. Cromer WE, Zawieja SD, Doersch KM, et al. Burn injury-associated MHCII + immune cell accumulation around lymphatic vessels of the mesentery and increased lymphatic endothelial permeability are blocked by doxycycline treatment. Lymphat Res Biol. 2018;16(1):56-64.

43. Peterson JR, De La Rosa S, Sun H, et al. Burn injury enhances bone formation in heterotopic ossification model. Ann Surg. 2014;259(5):993-8.

44. Xing D, Liu L, Marti GP, et al. Hypoxia and hypoxia-inducible factor in the burn wound. Wound Repair Regen. 2011;19(2):205-13.

45. Miyanaga T, Ueda Y, Miyanaga A, et al. Angiogenesis after administration of basic fibroblast growth factor induces proliferation and differentiation of mesenchymal stem cells in elastic perichondrium in an in vivo model: mini review of three sequential republication-abridged reports. Cell Mol Biol Lett. 2018;23:49.

46. Hwang C, Marini S, Huber AK, et al. Mesenchymal VEGFA induces aberrant differentiation in heterotopic ossification. Bone Res. 2019;7:36

47. Behr B, Sorkin M, Lehnhardt M, et al. A comparative analysis of the osteogenic effects of BMP-2, FGF-2, and VEGFA in a calvarial defect model. Tissue Eng Part A. 2012;18(9-10):1079-86.

48. Behr B, Tang C, Germann G, et al. Locally applied vascular endothelial growth factor A increases the osteogenic healing capacity of human adipose-derived stem cells by promoting osteogenic and endothelial differentiation. Stem Cells. 2011;29(2):286-96.

49. Agarwal S, Loder S, Cholok D, et al. Local and circulating endothelial cells undergo endothelial to mesenchymal transition (EMT) in response to musculoskeletal injury. Sci Rep. 2016;6:32514.

50. Medici D, Olsen BR. The role of endothelial-mesenchymal transition in heterotopic ossification. J Bone Miner Res. 2012;27(8):1619-22.

51. Zhang F, Qiu XC, Wang JJ, et al. Burn-related dysregulation of inflammation and immunity in experimental and clinical studies. J Burn Care Res. 2017;38(6):e892-9.

52. Sorkin M, Huber AK, Hwang C, et al. Regulation of heterotopic ossification by monocytes in a mouse model of aberrant wound healing. Nat Commun. 2020;11(1):722.

53. Ranganathan $\mathrm{K}$, Agarwal $\mathrm{S}$, Cholok D, et al. The role of the adaptive immune system in burn-induced heterotopic ossification and mesenchymal cell osteogenic differentiation. J Surg Res. 2016;206(1):53-61.

54. Kan C, Yang J, Na D, et al. Inhibition of immune checkpoints prevents injury-induced heterotopic ossification. Bone Res. 2019;7:33.

55. Yousuf Y, Jeschke MG, Shah A, et al. The response of muscle progenitor cells to cutaneous thermal injury. Stem Cell Res Ther. 2017;8(1):234.

56. Karlsen A, Soendenbroe C, Malmgaard-Clausen NM, et al. Preserved capacity for satellite cell proliferation, regeneration, and hypertrophy in the skeletal muscle of healthy elderly men. FASEB J. 2020;34(5):6418-36.

57. Hashimoto N, Kiyono T, Wada MR, et al. Osteogenic properties of human myogenic progenitor cells. Mech Dev. 2008;125(3-4):257-69.

58. Wu X, Walters TJ, Rathbone CR. Skeletal muscle satellite cell activation following cutaneous burn in rats. Burns. 2013;39(4):736-44

59. Wu X, Rathbone CR. Satellite cell functional alterations following cutaneous burn in rats include an increase in their osteogenic potential. J Surg Res. 2013;184(2):e9-16.

60. Peterson JR, Eboda ON, Brownley RC, et al. Effects of aging on osteogenic response and heterotopic ossification following burn injury in mice. Stem Cells Dev. 2015;24(2):205-13.

61. Ranganathan K, Peterson J, Agarwal S, et al. Role of gender in burn-induced heterotopic ossification and mesenchymal cell osteogenic differentiation. Plast Reconstr Surg. 2015;135(6):1631-41.

62. Thorpe CR, Ucer Ozgurel S, Simko LC, et al. Investigation into possible association of oxandrolone and heterotopic ossification following burn injury. J Burn Care Res. 2019;40(4):398-405.

63. Klifto KM, Dellon AL, Hultman CS. Risk factors associated with the progression from acute to chronic neuropathic pain after burn-related injuries. Ann Plast Surg. 2020;84(6S Suppl 5):382-5.

64. Strong AL, Agarwal S, Cederna PS, et al. Peripheral neuropathy and nerve compression syndromes in burns. Clin Plast Surg. 2017;44(4):793-803.

65. Choi JE, Di Nardo A. Skin neurogenic inflammation. Semin Immunopathol. 2018:40(3):249-59.

66. Rogoz K, Andersen HH, Kullander K, et al. Glutamate, substance P, and calcitonin gene-related peptide cooperate in inflammation-induced heat hyperalgesia. Mol Pharmacol. 2014;85(2):322-34. 
67. Niedermair T, Schirner S, Seebröker R, et al. Substance P modulates bone remodeling properties of murine osteoblasts and osteoclasts. Sci Rep. 2018;8(1):9199.

68. Tuzmen C, Verdelis K, Weiss L, et al. Crosstalk between substance $P$ and calcitonin gene-related peptide during heterotopic ossification in murine Achilles tendon. J Orthop Res. 2018;36(5):1444-55.

69. Lazard ZW, Olmsted-Davis EA, Salisbury EA, et al. Osteoblasts have a neural origin in heterotopic ossification. Clin Orthop Relat Res. 2015;473(9):2790-806.

70. Klein GL. The role of calcium in inflammation-associated bone resorption. Biomolecules. 2018;8(3):69.

71. Muschitz GK, Schwabegger E, Kocijan R, et al. Early and sustained changes in bone metabolism after severe burn injury. J Clin Endocrinol Metab. 2016;101(4):1506-15.

72. Rada B, Park JJ, Sil P, et al. NLRP3 inflammasome activation and interleukin-1 $\beta$ release in macrophages require calcium but are independent of calcium-activated NADPH oxidases. Inflamm Res. 2014;63(10):821-30.

73. Altman R, Bosch B, Brune K, et al. Advances in NSAID development: evolution of diclofenac products using pharmaceutical technology. Drugs. 2015;75(8):859-77.

74. Pountos I, Giannoudis PV, Jones E, et al. NSAIDS inhibit in vitro MSC chondrogenesis but not osteogenesis: implications for mechanism of bone formation inhibition in man. J Cell Mol Med. 2011;15(3):525-34.

75. Joice M, Vasileiadis Gl, Amanatullah DF. Non-steroidal anti-inflammatory drugs for heterotopic ossification prophylaxis after total hip arthroplasty: a systematic review and meta-analysis. Bone Joint J. 2018;100-B(7):915-22.

76. Migliorini F, Trivellas A, Eschweiler J, et al. NSAIDs for prophylaxis for heterotopic ossification after total hip arthroplasty: a bayesian network meta-analysis. Calcif Tissue Int. 2021;108(2):196-206.

77. Lisowska B, Kosson D, Domaracka K. Positives and negatives of nonsteroidal anti-inflammatory drugs in bone healing: the effects of these drugs on bone repair. Drug Des Dev Ther. 2018;12:1809-14.

78. Wheatley BM, Nappo KE, Christensen DL, et al. Effect of NSAIDs on bone healing rates: a meta-analysis. J Am Acad Orthop Surg. 2019;27(7):e330-6.

79. Hu ZH, Chen W, Sun JN, et al. Radiotherapy for the prophylaxis of heterotopic ossification after total hip arthroplasty: a systematic review and meta-analysis of randomized controlled trails. Med Dosim. 2021;46(1):65-73.

80. Pohl F, Hassel S, Nohe A, et al. Radiation-induced suppression of the Bmp2 signal transduction pathway in the pluripotent mesenchymal cell line $\mathrm{C} 2 \mathrm{C} 12$ : an in vitro model for prevention of heterotopic ossification by radiotherapy. Radiat Res. 2003;159(3):345-50.

81. Honore T, Bonan I, Salga M, et al. Effectiveness of radiotherapy to prevent recurrence of heterotopic ossification in patients with spinal cord injury and traumatic head injury: a retrospective case-controlled study. J Rehabil Med. 2020;52(5):jrm00066.

82. Rosenberg DM, Onderdonk B, Majeed NK, et al. Radiation-induced sarcoma after heterotopic ossification prophylaxis: a case report. JBJS Case Connect. 2019:9(4):e0146.

83. Chen HC, Yang JY, Chuang SS, et al. Heterotopic ossification in burns: our experience and literature reviews. Burns. 2009;35(6):857-62.

84. Chen JY, Fu CW, Ho HY, et al. Surgical treatment of postburn heterotopic ossification around the elbow: three case reports. Medicine. 2019;98(6):e14403.

85. Agarwal S, Loder S, Cholok D, et al. Surgical excision of heterotopic ossification leads to re-emergence of mesenchymal stem cell populations responsible for recurrence. Stem Cells Transl Med. 2017;6(3):799-806.

86. Maender C, Sahajpal D, Wright TW. Treatment of heterotopic ossification of the elbow following burn injury: recommendations for surgical excision and perioperative prophylaxis using radiation therapy. J Shoulder Elbow Surg. 2010;19(8):1269-75

\section{Publisher's Note}

Springer Nature remains neutral with regard to jurisdictional claims in published maps and institutional affiliations.

Ready to submit your research? Choose BMC and benefit from:

- fast, convenient online submission

- thorough peer review by experienced researchers in your field

- rapid publication on acceptance

- support for research data, including large and complex data types

- gold Open Access which fosters wider collaboration and increased citations

- maximum visibility for your research: over $100 \mathrm{M}$ website views per year

At BMC, research is always in progress.

Learn more biomedcentral.com/submissions 